\title{
Relações de Gênero e Sexismo na Educação Profissional e Tecnológica
}

Sabrina Fernandes Pereira Lopes sabrinafpl@yahoo.com.br Centro Federal de Educação Tecnológica de Minas Gerais, Belo Horizonte, Minas Gerais, Brasil.

\section{Raquel Quirino}

quirinoraquel@hotmail.com Centro Federal de Educação Tecnológica de Minas Gerais, Belo Horizonte, Minas Gerais, Brasil.

\begin{abstract}
RESUMO
No Brasil, a educação profissional técnica de nível médio, embora abrigue um número cada vez maior de mulheres, ilustra uma realidade de desigualdade, na qual os marcadores e estereótipos de gênero influenciam as escolhas profissionais das estudantes. Dados do INEP (2015) evidenciam que em todo o Brasil as mulheres se concentram em cursos cujas áreas de atuação reportam ao cuidado e a uma estreita ligação com o trabalho doméstico, tais como os cursos dos eixos tecnológicos: Ambiente e Saúde e Turismo, Hospitalidade e Lazer. O presente trabalho, derivado de uma pesquisa de mestrado, analisa as escolhas realizadas por alunas por um determinado curso técnico em detrimento de outros. Utilizou-se um levantamento documental em uma instituição da Rede Federal de Educação Profissional e Tecnológica e análise do discurso de alunas dos cursos com maior e menor concentração feminina na instituição. Os resultados evidenciam deslocamentos e permanências na dinâmica das relações de gênero durante o acesso e permanência na Educação Profissional e Tecnológica, destacam os preconceitos presentes nos cursos de maioria masculina e a continuidade da maior participação feminina em cursos relacionados às habilidades vistas como inatas nas mulheres. No entanto, evidencia-se uma crescente convicção das alunas sobre a assertividade de suas escolhas e uma resistência à ideia hegemônica de que áreas técnicas altamente feminizadas sejam desvalorizadas social e economicamente.
\end{abstract}

PALAVRAS-CHAVE: Relações de Gênero. Sexismo. Educação Profissional e Tecnológica. 


\section{INTRODUÇÃO}

Os estudos sobre relações de gênero visam problematizar e discutir as relações assimétricas, de dominação e de desigualdades existentes entre homens e mulheres na sociedade. Por sua vez, sexismo é um termo que se refere às discriminações sexuais e ao conjunto de ideias ou ações que privilegiam um indivíduo de determinado sexo. Embora seja um termo mais abrangente de discriminação sexual que pode atingir às pessoas de ambos os sexos e de orientações sexuais diversas, pelo histórico de subordinação e desigualdade imposto à mulher no decorrer do tempo, este termo é constantemente confundido com machismo (VON SMIGAY, 2008).

Discutem-se tais temas no presente artigo por meio do levantamento e análise de dados empíricos sobre o acesso, permanência, escolhas e perspectivas de alunas de Cursos Técnicos de Nível Ensino Médio, na modalidade integrada de uma instituição da Rede Federal de Educação Profissional e Tecnológica.

A abordagem adotada na pesquisa foi predominantemente qualitativa. A coleta de dados empíricos foi realizada por meio de uma triangulação sequencial de técnicas de pesquisa, buscando, conforme afirma Duarte (2009, p. 14), “[...] integrar diferentes perspectivas no fenômeno em estudo".

Foi realizado um levantamento documental dos dados do IBGE, IPEA e do Censo Escolar e no Registro Acadêmico da instituição buscando verificar o percentual de mulheres matriculadas em cada curso técnico no Brasil e naqueles ofertados no campus pesquisado, no período de 2010 a 2014

Posteriormente foram selecionadas, entre os cursos com maior e menor participação feminina no último quinquênio na instituição, alunas que participaram de entrevistas semiestruturadas. As entrevistas foram realizadas no período de agosto a setembro de 2016, utilizando-se elementos da pesquisa etnográfica, buscando, conforme afirma Silverman (2009, p. 157), compreender a forma como as alunas vivenciam e descrevem a sua realidade.

Foram entrevistadas onze alunas dos cursos técnicos integrados ao ensino médio, sendo sete do Curso Técnico em Hospedagem - curso que contém o maior número de alunas matriculadas - e quatro do Curso Técnico em Mecânica - que concentra o maior número de alunos.

Segundo Manzini (2012, p. 156),

A entrevista semiestruturada tem como característica um roteiro com perguntas abertas e é indicada para estudar um fenômeno com uma população específica: grupo de professores; grupo de alunos; grupo de enfermeiras, etc. Deve existir flexibilidade na sequência da apresentação das perguntas ao entrevistado e o entrevistador pode realizar perguntas complementares para entender melhor o fenômeno em pauta.

Portanto, buscou-se atender às essas características durante o processo da pesquisa. As entrevistas foram realizadas nas próprias dependências da instituição, com duração média de 30 minutos, gravadas em áudio e posteriormente transcritas na íntegra. Após a transcrição dos relatos das alunas foram selecionados trechos que auxiliaram na identificação de evidências de como foram 
feitas as suas opções pelo curso, de que forma o fato de ser mulher, assim como, outros aspectos interferiram nessa escolha e em suas experiências durante o curso. Os nomes das entrevistadas foram substituídos por nomes aleatórios para manter o anonimato e resguardar as identidades, conforme preconiza a ética em pesquisa.

Buscando a apreensão e desvelamento do fenômeno, a partir da fala das entrevistadas, foi utilizada a técnica de Análise Crítica do Discurso (ACD), proposta por Fairclough (2001), como forma de buscar a apreensão e desvelamento do fenômeno a partir da fala das entrevistadas, uma vez que o caráter desse tipo de estudo busca

[...] a análise das práticas discursivas que constroem as várias ordens sociais vigentes e como uma forma de investigação das formações discursivas que engendram as relações de poder, as representações e identidades sociais e os sistemas de conhecimento e crença (MELO, 2009, p. 09).

A base teórica para a análise dos dados empíricos está, predominantemente, embasada nas teorias da Sociologia do Trabalho Francesa, principalmente, as teorias das Relações Sociais de Sexo/Gênero e da Divisão Sexual do Trabalho propostas por Hirata $(1998,2002,2003,2007)$ e Kérgoat $(1989,2009,2010)$, fortemente influenciadas por pressupostos marxistas, o que possibilitou uma abordagem mais crítica do fenômeno estudado.

\section{RELAÇÕES DE GÊNERO NA ÁREA DE CIÊNCIA \& TECNOLOGIA (C\&T)}

Segundo Carvalho (2012, p. 01-02), as mulheres sempre produziram conhecimento, uma vez que a curiosidade, a capacidade científica e de pesquisa são inerentes a todos os seres humanos e não somente ao homem. Porém, esse conhecimento foi historicamente desvalorizado, pois,

o conhecimento tecnológico produzido pelas mulheres no ambiente doméstico não era considerado útil para o mercado capitalista e representava, digamos assim, um conhecimento de "segunda classe", desvalorizado e não científico. Assim, ciência e tecnologia foram construídas majoritariamente por homens, dentro de uma lógica masculina (CARVALHO, 2012, P. 02).

Conforme salienta Hirata (1998, p.06), na sociedade atual se evidencia uma grande desigualdade entre os gêneros e uma história marcada pelo sexismo, na qual as visões masculinas constantemente preponderaram no desenvolvimento tecnológico e, “(...) ainda hoje, o paradigma dominante é assexuado, que pretende ser universal, mas, na realidade, traduz um ponto de vista fundamentalmente masculino".

Para Carvalho (2012, p. 04),

[...] ciência e tecnologia foram construídas sob bases masculinas, com interesses masculinos e resultados que atendessem às necessidades masculinas cujos paradigmas científicos desta época estavam pautados na objetividade absoluta e na crença de uma neutralidade indiscutível. Acreditava-se que os homens, com sua racionalidade "exuberante", eram 
capazes de produzir um conhecimento revelador de verdades universais e definitivas.

A autora observa ainda que, mais da metade dos indivíduos que compõem a sociedade - as mulheres -, não têm suas perspectivas expressas nos rumos do desenvolvimento tecnológico e acrescenta que o crescimento da participação feminina desencadeia "[...] questionamentos sobre as dificuldades de inserção das mulheres nas ciências, a falta de reconhecimento pelo trabalho feminino por parte da comunidade científica, universitária e da sociedade (CARVALHO, 2012, p. 0607)".

Diversos estudos como os de Soares (2001), Olinto (2011) e Hayashi (2012), dentre outros, têm demonstrado um desequilíbrio de gênero nas áreas de C\&T. Segundo Stancki $(2003$, p. 07) essa divisão por gêneros nas áreas científicas e tecnológicas tende a ser atribuída às escolhas pessoais, porém é importante perceber que essas escolhas sofrem influências ou mesmo podem ser condicionadas. O histórico de ciência e tecnologia, sendo desenvolvidas predominantemente por homens, também concedeu um espaço de formação hostil às mulheres, o que gera influências peculiares em suas opções.

Rosemberg $(2013$, p. 89$)$ afirma que as escolhas realizadas por mulheres se devem a uma "sabedoria de conciliação ou senso de realidade", que leva as mulheres a considerarem os diversos aspectos que compõem sua situação na sociedade e, por essa razão, a escolher cursos pouco especializados, não técnicos e mais generalistas, que permitam uma maior gama de possibilidades de emprego, mesmo que sejam subempregos. E mesmo a entrada de mulheres em áreas tradicionalmente masculinas se dá, em geral, com a manutenção dos estereótipos de gênero.

As pessoas ao se inserirem em áreas masculinas ou femininas permanecem sendo vistas por meio das suas características sociais de gênero, o que acarreta a divisão sexual do trabalho também no interior das áreas, pois homens e mulheres acabam sendo levados, por opção, condicionamento ou mesmo falta de opção a desempenharem atividades próprias de seu sexo (STANCKI, 2003, p. 10).

Segundo Carvalho (2012), para o senso comum, o baixo número de mulheres que estudam ou trabalham nas áreas de C\&T é explicado por suas características inatas, em uma suposta inaptidão biológica ou emocional para exercerem funções no universo das áreas das chamadas ciências duras. Porém, é necessária uma apreciação mais profunda para se evidenciar os reais aspectos que influenciam o afastamento das mulheres desse meio.

Assim,

[...] uma questão importante para os estudos de CT e G [Ciência, Tecnologia e Gênero] é a tensão que se cria com a participação cada vez maior das mulheres nas ciências e nas universidades. Surgem questionamentos sobre as dificuldades de inserção das mulheres nas ciências, a falta de reconhecimento pelo trabalho feminino por parte da comunidade científica, universitária e da sociedade (CARVALHO, 2012, p. 07). 
Entre os obstáculos encontrados pelas mulheres para ingressar e permanecer nas áreas de Ciência e Tecnologia, segundo o Encontro Nacional de Núcleos e Grupos de Pesquisas 2005 - Pensando Gênero e Ciência (BRASIL, 2006) destacamse: o preconceito da família e da sociedade contra a mulher que busca uma carreira que exige grande dedicação; a dupla jornada causada pelo acumulo do trabalho científico com as atividades domésticas; a tensão na relação conjugal e a requisição de realizações profissionais mais substanciais do que as dos homens para serem aceitas pelos pares.

Para Toledo (2001, pg. 35), o processo gerador da desigualdade de gênero no mundo do trabalho, tanto no acesso, quanto na valorização do trabalho visto como feminino, passa por três estágios: (i) a demarcação de atividades que devem ser realizadas por homens e mulheres; (ii) a caracterização dessas atividades realizadas por mulheres como inerentemente femininas e, de forma análoga, atividades atribuídas aos homens como masculinas e, por fim; (iii) tratamento diferente àqueles que realizam atividades femininas ou masculinas, demonstrando que "a desigualdade das mulheres é um processo que começa com a divisão sexual do trabalho e se consolida com a constituição dos gêneros sociais". Assim as falas das alunas entrevistadas foram analisadas segundo tais estágios.

\section{AS ESCOLHAS DAS ALUNAS}

Dos inúmeros relatos das alunas entrevistadas, alguns excertos foram escolhidos, de forma a retratar suas percepções acerca das questões de pesquisa. Para manter o sigilo recomendado pelo Comitê de Ética, seus nomes foram substituídos por nomes fictícios e não foram feitas correções das falas, a fim de se manter, ao máximo, a fidedignidade dos discursos das alunas.

Entre as entrevistadas que optaram pelo Curso Técnico em Mecânica predomina certo modelo existente em suas famílias. $\mathrm{O}$ fato de terem parentes próximos inseridos nessa área técnica levou-as a desenvolverem uma relação afetiva e de curiosidade em relação à profissão.

Virgínia, aluna do Curso Técnico em Mecânica, cujo avô trabalhou com mecânica automobilística, declara seu entusiasmo pela área e a súbita decepção devido à sua desinformação sobre a ênfase dada ao curso escolhido:

Quando eu entrei no curso técnico em mecânica achei que seria mecânica automobilística, igual ao que o meu vô fazia. Eu sempre gostei muito de carro; quando eu via meu avô trabalhando pensava: que coisa magnífica, como funciona tudo isso? Tanta coisa junta e olha, funcionando! Mas quando eu entrei na mecânica vi que era mecânica industrial e eu fiquei decepcionada. Pensei: nossa, como é que vai ser agora? (Virgínia, Aluna do curso Técnico em Mecânica. grifos nossos).

Em sua fala Virgínia destaca o funcionamento mecânico do automóvel como coisa magnífica, mostrando seu interesse pela profissão do avô. Discurso semelhante é feito por Lívia, aluna do mesmo curso:

Eu sou muito curiosa para saber como as coisas funcionam, eu sou curiosa pra saber porque usamos um material ao invés de outro num sistema mecânico, porque aquele material e quais as propriedades, eu sou muito 
curiosa em saber realmente como as coisas funciona. (Livia - Aluna do curso Técnico em Mecânica).

As falas de ambas as alunas revelam deslumbramento e curiosidade pelo funcionamento dos artefatos tecnológicos evidenciando que tal interesse por tecnologia acontece independentemente do gênero. Porém, ao prosseguirem seus relatos, evidencia-se uma vontade de adentrar em universo, um tanto inacessível a elas, de um mundo reservado apenas aos homens da família.

As conversas sobre mecânica eram limitadas àquele círculo ali, meu pai, meu avô, meu tio e outras pessoas da minha família que tem um contato a mais com a mecânica. Eles nunca conversaram realmente sobre isso comigo (Lívia - Aluna do curso Técnico em Mecânica).

Tal discurso é corroborado por Velho e León (1998) quando afirma que a falta de estímulo da família é um dos aspectos que mais afasta as meninas das áreas científicas e tecnológicas.

Também Carvalho (2012) ressalta que a ciência e tecnologia, como são conhecidas na esfera pública, foram construídas sobre bases patriarcais. Aqui se evidencia uma intercessão dessa esfera pública com a privada, pois, aparece uma divisão dentro da própria família, entre os homens que discutem o fazer tecnológico excluindo dessas conversas as mulheres, uma vez que a elas estão reservados saberes e espaços de atuação de outra natureza.

Porém, o argumento de Velho e León (1998) que atesta que a família tende a afastar as mulheres das carreiras mais tecnologizadas e aproximá-las daquelas tradicionalmente vistas como femininas é negada pelas alunas do curso técnico em hospedagem. A escolha delas pelo curso é vista com pesar ou indiferença pelas famílias e nenhuma delas descreve qualquer incentivo da família para optarem por tal área considerada mais leve e adequada às mulheres.

Ainda que a percepção de que determinados cursos não são comumente vistos como adequados para mulheres, o que mais pesa no posicionamento dessas famílias é o prestígio social e econômico da profissão, uma vez que, conforme descrito por Toledo (2001), as profissões vistas como femininas passam por um processo de desvalorização econômica e social, assumindo uma posição hierarquicamente inferior ao trabalho visto como masculino. As famílias das alunas não desejam ter as filhas em um curso inferior ou socialmente malvisto:

Olha, meu pai queria que eu fizesse alguma coisa mais técnica. Queria que eu fizesse eletrônica ou edificações. Sei lá! Pra eu virar engenheira. E eu falei, mas eu quero hospedagem e ele: ah, mas hospedagem? E eu, ah, é área de humanas e é isso que eu gosto (Raquel - aluna do Curso Técnico em Hospedagem).

Quando eu estava para entrar aqui, tinha aquele estereótipo, né? Minha prima mais velha, por parte de pai, estudou aqui antes e quando eu falei: Vou fazer vestibular, vou tentar para hospedagem, ela começou a me encher o saco. Ela faz química e acha que por isso é melhor que eu, mas na minha cabeça não passava nem a ideia de fazer outro curso. Mas a questão é que existe um certo estereótipo quando as pessoas olham para hospedagem. Até as pessoas que iam ao nosso stand na mostra de cursos diziam: Ah, hospitalidade, né? Com tanto curso bom... Era pouco caso e tal (Anna-Curso Técnico em Hospedagem). 
Assim, evidencia-se uma situação paradoxal diante das escolhas dessas alunas. Há uma pressão cultural e social para que suas escolhas sejam por cursos supostamente condizentes com sua feminilidade, porém, ao fazerem tais escolhas essas são desvalorizadas por se tratarem de cursos cujas áreas são econômica e socialmente vistas como menos relevantes. Surgem nesse paradoxo a dicotomia e a dupla pressão: que mantenham o estereótipo de gênero e ao mesmo tempo que o superem.

Quando questionadas sobre as escolhas realizadas, todas as entrevistadas afirmaram acreditar tê-las feito acertadamente, porém somente entre as entrevistadas do Curso Técnico em Mecânica houve a manifestação da vontade de seguir uma carreira diretamente relacionada ao curso técnico, após a sua conclusão. As alunas do Curso Técnico em Hospedagem reafirmaram que fizeram a escolha pelo curso por se tratar do único ofertado na instituição que tem raízes nas ciências humanas e como experimentação e preparação para uma posterior graduação.

Os discursos de várias entrevistadas reforçam que a instituição lhes proporciona a possibilidade de debater e refletir sobre as relações de gênero. Todas revelaram acompanhar essa questão na escola e buscar modificações, tanto pessoais, quanto em suas famílias e comunidades. Especialmente citaram um grupo formado na instituição que promove atividades sobre temas relevantes para dar-lhes suporte nos casos de machismo, lesbofobia e racismo.

Embora sejam muito jovens, todas entre 15 e 17 anos, as entrevistadas já conseguem ter uma visão de mundo e uma posição bem definida em relação aos estereótipos e sexismo:

Meu maior número de amigos são homens. Quando eu era mais nova tinha aquele discurso: A mulher é muito difícil, homem é mais fácil, depois eu entendi que não. (...) E relacionamentos afetivos, quando eu tinha 13 anos, eu tive o meu primeiro namoro sério, e foi horrivel, eu não tinha noção do quanto abusivo foi. No final do ano passado que eu parei pra pensar: nossa, onde eu estava com a cabeça? E do quanto eu abria mão de mim para o relacionamento (Virgínia - Curso Técnico em Mecânica)

Antes de eu entrar, pensava: que saco, só tem mulher nesse curso, imagina quando esse povo começar a falar, depois que foi passando o tempo até dei graças a Deus, porque eu não ia aguentar. A gente acaba se unindo muito, a gente conhece os problemas umas das outras (Célia - Curso Técnico em Hospedagem).

As entrevistadas externalizam terem feito suas escolhas cientes das tensões de gênero presentes nos cursos, e, em cada curso, elas se rebelam de algum modo contra os princípios da divisão sexual do trabalho e das características do sexismo. As alunas do Curso Técnico em Mecânica, por exemplo, verbalizam a vontade de romper com o princípio da separação do trabalho entre os sexos e a segregação das mulheres em determinadas áreas. Rompendo com estereótipos e transgredindo as tradições, essas meninas se ingressaram em uma área hegemonicamente masculina, ainda fechada às mulheres e se negam a continuar serem deixadas de lado: quis fazer e tô fazendo e tô dando conta! Se, se homens fazem eu também 
posso fazer. Eles não são melhores do que nós... (Luísa - Curso Técnico em Mecânica).

A gente tem um time unido aqui no curso e estamos tentando nos unir cada vez mais contra essa coisa de ter só homens no Curso Técnico em Mecânica. Eles não precisam ser protagonistas sempre (Virgínia - Curso Técnico em Mecânica).

Já no Curso Técnico em Hospedagem, embora a escolha das alunas tenha se dado de forma consciente por um curso majoritariamente feminino, evidencia-se o sexismo por parte da instituição e também o desejo de romper com a desvalorização da área, o que ocorre justamente por ser ocupada majoritariamente por mulheres. Suas falas não questionam se suas escolhas foram acertadas ou se deveriam ter optado por outro curso supostamente mais valorizado. O que desejam é que o curso escolhido não seja menosprezado e desvalorizado diante dos outros cursos técnicos mais masculinizados da instituição:

A gente tá tentando mudar essa visão, mas é muito, muito, muito forte essa coisa de ser curso para mulher, de ser curso mais fácil, que só menina que faz, que todas as meninas de hosp. têm que ser bonitas. Quando eu fui entrar aqui um amigo meu falou que a fama é que a turma de hospedagem era uma turma cheia de mulher bonita. Hospedagem é mulher bonita, só isso. Um desaforo! Somos estudantes e queremos ser profissionais como qualquer um deles. (Anna-Curso Técnico em Hospedagem).

Acho que a instituição deveria valorizar mais o nosso curso. Porque eles não oferecem uma estrutura melhor pra gente como a dos outros cursos? Parece que é curso de mulherzinha, que não precisa de laboratório de estrutura, de materiais. Sei lá, acho isso um absurdo. Parece que só porque tem mais mulher o curso vale menos. (Alice - Curso Técnico em Hospedagem).

Outra questão que aparece marcada nas falas das alunas é como o curso técnico integrado ofertado pela instituição consome grande parte do seu tempo, privando-as de estar mais em contato com a família e amigos.

Aquela história de que a sua casa agora é só seu dormitório é muito real, é verdade. Você toma banho, come alguma coisa e já apaga, ou vira a noite estudando, nem parece que você acorda na sua casa, parece que você acorda aqui já (Célia - Curso Técnico em Hospedagem).

É... Eu fico muito tempo aqui; mecânica é um curso que tem uma grade curricular muito extensa, então eu saio de casa, venho pra cá, faço as minhas coisas, às vezes enrolo um pouquinho aqui, vou pra casa, tomo banho, janto, converso um pouquinho com a minha família, faço as coisas que eu tenho que fazer, durmo e no outro dia é a mesma coisa (Lívia - Curso Técnico em Mecânica).

Não obstante essa rotina dedicada aos estudos, a realização de tarefas domésticas por parte das meninas entrevistadas ainda é uma realidade. Algumas relatam desdobrarem-se para ajudar e, outras, alegam serem cobradas pelos seus familiares a exercerem o papel destinado à mulher no ambiente doméstico e contribuir com as atividades de casa. Uma delas afirma:

Tenho que fazer, tenho que conciliar, é uma loucura, ainda mais que tenho 
tenho vago e daí tenho que vir pra cá. Só fazemos as tarefas de casa eu e minha avó (Carolina - Curso Técnico em Hospedagem).

Essa realidade vivenciada pelas alunas cria uma situação de tensão, pois, conforme afirma Hirata (2002), a despeito da entrada massiva de mulheres no mercado de trabalho, a divisão sexual do trabalho doméstico não sofreu alterações substanciais. Assim, o trabalho que era repassado a elas acaba recaindo sobre outras mulheres, como caso de Carolina, que divide as tarefas domésticas com a avó. Porém, nenhuma delas relatou que trabalho doméstico é realizado pelos homens da sua família:

Eu arrumo meu quarto, às vezes arrumo cozinha. Minha mãe faz as tarefas domésticas e meu pai ele nunca ajuda em casa, muito difícil ele lavar alguns pratos. (Raquel - Curso Técnico em Hospedagem).

Assim, o trabalho doméstico assumido pelas mulheres libera os homens para o trabalho produtivo, embora ninguém libere a mulher que trabalha fora (ou estuda) do trabalho doméstico. Uma opção encontrada, para aquelas de melhor renda é a possibilidade de externalização do trabalho doméstico para outras mulheres (KERGOAT, 2010, p. 94).

Com essa rotina alterada, minha mãe acabou optando por contratar uma faxineira, a gente não dá conta sozinha, não. (Luísa - Curso Técnico em Mecânica).

Já aquelas que não têm a opção de terceirizar as tarefas domésticas, essa tensão se torna ainda mais evidente e se manifesta na fala de algumas entrevistadas em relação ao seu futuro. Para outras, manifesta-se a culpa por não poderem mais realizar as atividades de casa:

Eu fico com pena da minha mãe, queria fazer mais, mas não tem como, a rotina não deixa. Antes, quando eu estava em casa, ela ficava mais folgada... (Luisa - Curso Técnico em Mecânica).

Na minha casa eu chego tarde e, às vezes, eu fico triste porque teve um dia que eu tinha muita coisa mesmo para fazer, não ia dar tempo e eu ia ter que ficar a noite estudando e a minha avó virou e falou assim: filha você me ajuda aqui? e eu fiquei nervosa, falei: Vó, eu não posso fazer isso, eu tenho que me concentrar aqui, eu fiquei bem triste porque a minha avó tem 85 anos e daí eu não pude ajudar ela. É uma coisa pequena, mas eu fiquei nervosa, eu não pude fazer a vontade da minha avó. (Lívia - Curso Técnico em Mecânica).

Evidencia-se também um forte sexismo nos cursos de maioria masculina, sobretudo por parte dos professores, porém, as alunas afirmam tentativas de rompimento dos estereótipos de gênero:

Os professores pensam que a gente vai ficar pedindo ajuda pros meninos. $\mathrm{Na}$ tornearia, por exemplo, a minha dupla é uma menina e a gente brilhou até agora. A gente realmente teve um desempenho bom. Os meninos da minha sala eu acho que eles não veem que realmente seja um campo para mulheres ou para homens. Mas os professores... Eu já escutei: se o seu desenho não ficar limpinho você não vai casar e eu fiquei pensando: meu Deus! (Lívia Curso Técnico em Mecânica). 
Eu sou muito de me impor, mas tem meninas que não. Então você vê que sofre uma discriminação. Eu penso: será que ela vai dar conta do curso? Eu mesma já me peguei pensando nisso. Tem uma menina na sala, ela é muito fofinha, delicada, não é só a aparência dela, ela fisicamente é, eu já me peguei pensando será que ela vai conseguir? Tem partes que são pesadas, eu tive problema, quando fui mexer numa máquina e não consegui, por causa de força, tive que pedir alguém pra me ajudar e fico pensando nela será que vai conseguir? Será que vão ter a paciência que ela precisa? Será que vão ensinar? Porque ela vai precisar. A gente vai precisar de uns macetes, as máquinas não são leves (Virgínia - Curso Técnico em Mecânica).

O relato de Virgínia demonstra uma percepção do gênero como algo natural e biológico. Porém, um equipamento pesado e de difícil execução não é um problema apenas para as meninas "fofinhas e delicadas", mas também os meninos, que não têm uma constituição física e força que lhes dê condições de executar o trabalho. Também eles precisarão de ajuda. Nesse caso, não são as relações de gênero que definem a incompetência técnica das mulheres, mas, sim, a falta de organização e planejamento por parte da instituição que não contempla em suas rotinas de ensino prático as diferenças entre seus alunos, independentemente do gênero a que pertencem.

As falas apresentadas a corroboram as teorias de Kérgoat (2010), de que, embora as relações de gênero passem por deslocamentos, a existência de tensão ainda permanece.

\section{CONCLUSÕES CONSIDERAÇÕES FINAIS}

O Estado deve cumprir papel ativo na defesa dos diretos da mulher e lançar mão de estratégias para proteger a trabalhadora frente às imposições do mercado. Reveste-se de especial importância para as mulheres o perigo do desemprego, uma vez que grande parte dos lares brasileiros é chefiada por mulheres. A precariedade do trabalho feminino se revela através do fato de receberem salários menores que o dos homens.

Durante a análise das entrevistas foi possível perceber que a maioria das alunas não apresentava um conhecimento sistematizado sobre as suas futuras áreas de atuação antes do ingresso nos cursos, mas já se posicionavam contrariamente a valorização desigual das atividades vistas como femininas e à negação de seu acesso aos locais de prestígio social. Suas falas defendem abertamente as ciências humanas como conhecimento válido e a capacidade feminina para atuar em qualquer atividade, porém ainda estão presentes traços do discurso hegemônico, principalmente no que tange à capacidade física para labutar em áreas que requerem um trabalho visto como mais pesado, ignorando os avanços tecnológicos que facilitam sua realização.

Os aspectos presentes nas escolhas das alunas são de ordem variada e não se apresentam de forma homogênea e linear, contradizendo-se, e, muitas vezes, subvertendo o senso comum e as teorias já criadas a esse respeito.

Entre os aspectos analisados figuram, preponderantemente, aqueles de ordem familiar, social e cultural. Para as alunas do Curso Técnico em Mecânica a 
influência familiar aparece de forma mais evidente na opção por uma carreira que já está estabelecida no grupo familiar e no desejo de fazer parte de um grupo reservado apenas para os homens da família. Já no Curso Técnico em Hospedagem evidencia-se uma relação antagônica e paradoxal diante das pressões sofridas pelas alunas para se adequarem às profissões "de mulher" e a decepção dos parentes quando essa escolha leva a uma profissão social e economicamente desvalorizada

Nos dois cursos analisados, com maior e menor participação feminina, percebe-se a luta pela modificação da situação da mulher. As alunas do Curso Técnico em Mecânica buscam a desconstrução da segregação horizontal adentrando em grupos anteriormente reservados apenas aos homens - e, também a segregação vertical - buscando opções de cursos para sua ascensão profissional futura. Já aquelas que optaram pelo Curso Técnico em Hospedagem tradicionalmente feminino -, a escolha não foi feita às cegas. As alunas demonstram conhecer essa realidade sexista e, embora ingressem em áreas profissionais ocupadas por maioria feminina, assumem uma postura combativa contra a desvalorização dos conhecimentos ditos femininos, de sua naturalização e, portanto, da não exigência de formação específica. Infere-se que a escolha por um curso com histórico de grande presença feminina aparece mais como um ato de rebeldia, uma negação da valorização das ciências exatas em detrimento das ciências humanas, do que como uma aceitação tácita das regras sexuadas socialmente estabelecidas.

Após seu ingresso, as alunas descrevem uma situação que manifesta claramente o princípio da hierarquia nos cursos técnicos ofertados pela instituição: existem cursos para homens e cursos para mulheres e os cursos para homens valem mais do que o curso para as mulheres, confirmando os princípios organizadores da divisão sexual do trabalho descritos por Kérgoat (1998). Os discursos reproduzem a necessidade constante das mulheres de lutarem para se estabelecer nos cursos, seja pela imposição de sua presença e denúncia do sexismo presente ou pela reafirmação da importância social que seu curso tem para a sociedade. 


\title{
Gender Relations and Sexism in Professional and Technological Education
}

\begin{abstract}
In Brazil, the higher-level professional technical education, while harboring an increasing number of women, illustrates a reality of inequality in which markers and gender stereotypes influence the professional choices of students. Data from the INEP (2015) show that all over Brazil, women are concentrated in courses in which areas of work relate to care and a close connection with domestic labor, such as courses in technology: Environment, Health, Tourism, Hospitality and Leisure. The present work, derived from a master's research, analyzes the choices made by students by a certain technical course to the detriment of others. A documentary survey was used in an institution of the Federal Network of Professional and Technological Education and analysis of the discourse of students of the courses with greater and lesser female concentration in the institution. The results show the dislocations and permanence in the dynamics of gender relations during the access and permanence in Vocational and Technological Education, highlighting the preconceptions present in the majority male courses and the continuity of greater female participation in courses related to abilities seen as innate in women. However, there is a growing conviction among the students about the assertiveness of their choices and a resistance to the hegemonic idea that highly feminized technical areas are devalued socially and economically.
\end{abstract}

KEYWORDS: Gender Relationships. Sexism. Professional and Technological Education. 


\section{REFERÊNCIAS}

BILY, Sherry; MANOOCHECRI, Gus. Breaking the glass ceiling. American Business Review, v. 13, n. 2, p. 33-40, 1995.

BRUSCHINI, Maria Cristina Aranha. Trabalho das mulheres no Brasil: continuidades e mudanças no período 1985-1995. São Paulo. Fundação Carlos Chagas,1998. 85p.

CARVALHO, Marilia Gomes, Gênero e os Paradigmas Científico. In: Anais Congreso Iberoamericano de Ciencia, Tecnología y Género, 2012, 9, Sevilla, OEI, 2012.1-9.

CHASSOT, A. Alfabetização científica: uma possibilidade para a inclusão social.Rev. Bras. Educ., Rio de Janeiro, n. 22, p. 89-100, 2003.

FAIRCLOUGH, Norman. Discurso e mudança social. Brasília: Universidade de Brasília, 2001.

HIRATA, Helena. Reestruturação produtiva, trabalho e relações de gênero. Revista Latino-americana de Estudos do Trabalho, v. 4, n. 7, p. 5-27, 1998.

HIRATA, Helena et. AL. (orgs.). Dicionário Crítico do Feminismo. São Paulo: UNESP, 2009.

HIRATA, Helena. Dinâmica e Consubstancialidade das Relações Sociais. Novos Estudos. CEBRAP 86, mar. 2010

HIRATA, Helena. Nova divisão sexual do trabalho?: um olhar voltado para a empresa e a sociedade. Boitempo, 2002a.

HIRATA, Helena. Tecnologia, formação profissional e relações de gênero no trabalho. Revista Educação e Tecnologia, Belo Horizonte, n.6, p. 144-156. 2003.

HIRATA, Helena. Division sexuelle du travail et rôle de l'état: I'exemple brésilien. Critiques de l'économie politique, v. 17, p. 40-67, 1981.

HIRATA, Helena. Globalização e divisão sexual do trabalho. Cadernos Pagu, Campinas, n. 17-18, p. 139-156, $2002 . \quad$ Disponível em: $<$ http://www.scielo.br/scielo.php?script=sci_arttext\&pid=S010483332002000100 006\&lng=pt\&nrm=iso >. Acesso em: 12 dez. 2016.

HIRATA, Helena. O trabalho de cuidado aos idosos no Japão e alguns aspectos de comparação internacional. Mediações, Londrina, v. 17 n. 2, p. 157-165, Jul./Dez. 2012

IBGE - Instituto Brasileiro de Geografia e Estatística. Estatísticas de Gênero: Uma análise dos resultados do Censo Demográfico 2010. 1. ed. Rio de Janeiro: IBGE, 2014. 159p.

KÉRGOAT, Daniele. Da divisão do trabalho entre os sexos. Tempo Social, v. 1, n. 2, p. 88-96, 1989.

LIMA, Betina Stefanello. O labirinto de cristal: as trajetórias das cientistas na Física. Estudos Feministas: Florianópolis, setembro-dezembro, 2013.

MOURA, Dante Henrique. Educação básica e educação profissional e tecnológica: 
OLINTO, Gilda. A inclusão das mulheres nas carreiras de ciência e tecnologia no Brasil. Inc. Soc., Brasília, DF, v.5 n.1, p. 68-77, jul./dez., 2011

QUIRINO, Raquel. Mineração também é lugar de mulher! Desvendando a (nova?!) face da divisão sexual do trabalho na mineração de ferro. Tese de Doutorado. Faculdade de Educação da Universidade Federal de Minas Gerais, 2011.

SAVIANI, Demerval. Trabalho e educação: fundamentos ontológicos e históricos. Rev. Bras. Educ., Rio de Janeiro, v. 12, n. 34, p. 152-165, Apr. 2007. Disponível em: $<$ http://www.scielo.br/scielo.php?script=sci_arttext\&pid=S1413-

24782007000100012\&Ing=en\&nrm=iso>. Acesso em: 07/nov./ 2015.

SOARES, Manoel Jesus Araújo. Uma nova ética do trabalho nos anos 20-Projeto Fidélis Reis. Série Documental-Relatos de Pesquisa, n. 33, p. 98-105, 1995.

SOARES, Thereza Amélia. Mulheres em ciência e tecnologia: ascensão limitada. Química Nova, São Paulo, v. 24, n. 2, p. 281-285, Abril de 2001 . Disponível em $<$ http://www.scielo.br/scielo.php?script=sci_arttext\&pid=\$010040422001000200 020\&lng $=e n \& n r m=i s o>$.

STANCKI, Nanci. Divisão sexual do trabalho: a sua constante reprodução. I Ciclo de debates em Economia Industrial, Trabalho e Tecnologia, PUC-SP, 2003. http://www.pucsp.br/eitt/downloads/eitt2003_nancistancki.pdf. Acesso em 25 nov. 2015.

RODRIGUES, José. Celso Suckow da Fonseca e a sua "História do ensino industrial no Brasil". Revista Brasileira de História da Educação, v. 2, n. 2 [4], p. 47-74, 2002.

TOLEDO, Cecília. O gênero nos une a classe nos divide. Cadernos Marxistas. São Paulo: Xamã, 2001.

VELHO, Lea; LEÓN, Elena. A construção social da produção científica por mulheres. Cadernos Pagu, Campinas, n.10, p. 309-344, 1998.

VON SMIGAY, Karin Ellen. Sexismo, homofobia e outras expressões correlatas de violência: desafios para a psicologia política. Psicologia em Revista, [S.I.], v. 8, n. 11, p. 32-46, out. 2008. ISSN 1678-9563. Disponível em: <http://periodicos.pucminas.br/index.php/psicologiaemrevista/article/view/136 >. Acesso em: 17/ jul./ 2016.

Recebido: 18 set. 2017

Aprovado: 11 nov. 2017.

Como citar:

LOPES, Sabrina Fernandes Pereira;QUIRINO,Raquel. Relações de Gênero e Sexismo na Educação

Profissional e Tecnológica. Cad. Gên. Tecnol., Curitiba, v. 10, n. 36, p. 58-71, jul./dez. 2017.

Correspondência:

Sabrina Fernandes Pereira Lopes. Rua Vereda das Brumas, 288, Residencial Veredas das Gerais

34012-010 - Nova Lima - MG.

Direito autoral:

Este artigo está licenciado sob os termos da Licença Creative Commons-Atribuição 4.0 Internacional. 